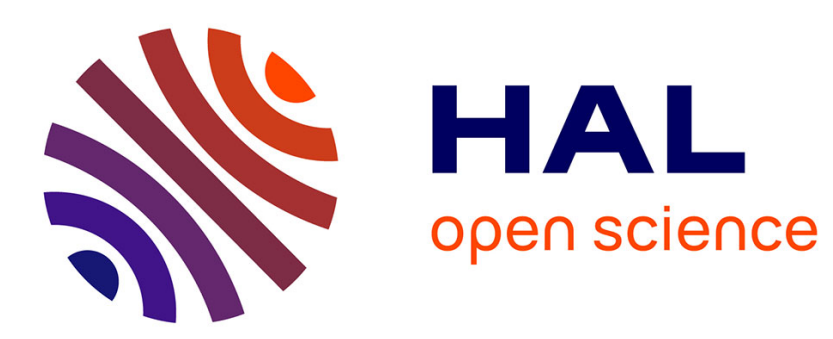

\title{
Large Eddy Simulation of Pre-Chamber Ignition in an Internal Combustion Engine
}

\author{
Quentin Malé, Gabriel Staffelbach, Olivier Vermorel, Antony Misdariis, \\ Frédéric Ravet, Thierry Poinsot
}

\section{- To cite this version:}

Quentin Malé, Gabriel Staffelbach, Olivier Vermorel, Antony Misdariis, Frédéric Ravet, et al.. Large Eddy Simulation of Pre-Chamber Ignition in an Internal Combustion Engine. Flow, Turbulence and Combustion, In press, 10.1007/s10494-019-00026-y . hal-02094525v2

\section{HAL Id: hal-02094525 \\ https://hal.science/hal-02094525v2}

Submitted on 15 May 2019

HAL is a multi-disciplinary open access archive for the deposit and dissemination of scientific research documents, whether they are published or not. The documents may come from teaching and research institutions in France or abroad, or from public or private research centers.
L'archive ouverte pluridisciplinaire HAL, est destinée au dépôt et à la diffusion de documents scientifiques de niveau recherche, publiés ou non, émanant des établissements d'enseignement et de recherche français ou étrangers, des laboratoires publics ou privés. 
This is a pre-print of an article published in:

Flow, Turbulence and Combustion.

The final authenticated version is available online at:

https://doi.org/10.1007/s10494-019-00026-y

\title{
Large eddy simulation of pre-chamber ignition in an internal combustion engine
}

\author{
Quentin Malé · Gabriel Staffelbach • \\ Olivier Vermorel • Antony Misdariis • \\ Frédéric Ravet · Thierry Poinsot
}

This is a pre-print of an article published in: Flow, Turbulence and Combustion.

The final authenticated version is available online at:

https://doi.org/10.1007/s10494-019-00026-y

\begin{abstract}
Using homogeneous lean mixtures is an efficient way to reduce fuel consumption and pollutant emissions in internal combustion engines. However, lean combustion requires breakthrough technologies to induce reliable ignition and fast combustion. One of these technologies uses pre-chamber to create multiple hot turbulent jets and provide ignition sites for the lean mixture. In this paper, the behaviour of a pre-chamber ignition system used to ignite the main chamber of a real engine is studied using large eddy simulation with direct integration of analytically reduced chemistry using the dynamic thickened flame model. The large eddy simulation allows to analyze the flow entering and leaving the prechamber, to measure the cooling and quenching effects introduced by the hot gas passages through the ducts connecting pre- and main chambers and to analyze the ignition and combustion sequences. For the case studied here, small amount of flame kernels are exhausted from the pre-chamber. Hot products penetrate the main chamber, disperse and mix with the fresh reactants and lead to ignition. The combustion in the main chamber starts in a distributed reaction mode before reaching a flamelet propagation mode.
\end{abstract}

Keywords Pre-chamber ignition - Turbulent jet ignition · Internal combustion engines $\cdot$ Large eddy simulation

Quentin Malé · Gabriel Staffelbach · Olivier Vermorel · Antony Misdariis CERFACS, 42 Avenue Gaspard Coriolis, 31057 Toulouse Cedex 01, France

E-mail: male@cerfacs.fr

Quentin Malé · Frédéric Ravet

Renault SAS, 1 Avenue du Golf, 78288 Guyancourt Cedex, France

Thierry Poinsot

CNRS, IMFT, 1 Allée du Professeur Camille Soula, Toulouse Cedex 31400, France 


\section{Introduction}

Transport almost entirely relies on Internal Combustion Engine (ICE) burning petroleum-derived fuel. While the global demand for transport energy is large and is increasing, changing transport policy and improving ICE is of major importance because of the climate and pollution impact on earth. One way to improve ICE is to use homogeneous lean combustion. Indeed, this is one of the most promising paths to reduce specific fuel consumption and exhaust pollutant emissions 9. It offers better efficiency through lower pumping losses, lower heat losses and higher heat capacity ratio in comparison with stoichiometric combustion. Homogeneous lean combustion also produces low pollutant emissions. However, lower burning velocities and harder ignition prevent classical spark ignition engines to be operated in very lean regimes [36, 25]: spark ignition of lean mixture causes erratic combustion, misfires and partial burns. Thus, burning homogeneous lean mixture still remains a major challenge that requires breakthrough technologies to ignite the mixture and produce fast combustion. Experiments [22,14,15,2,39] show that pre-chamber ignition systems can pave the way towards lean combustion in ICE. These systems produce multiple high energy ignition sources and turbulence injection which result in a reliable ignition and a fast combustion of the main charge. This pushes back the air dilution limit, which is due to misfires, partial burns and cycle-to-cycle combustion variations. Furthermore, the fast combustion induced by these systems not only directly increases engine efficiency but also allows to increase the knock limited compression ratio which further increases the engine efficiency.

In pre-chamber ignition systems, an auxiliary charge is ignited inside a smaller pre-chamber linked to the main chamber by multiple ducts. Combustion inside the pre-chamber creates a pressure increase due to thermal expansion. The pressure difference between the two chambers creates a flow out of the pre-chamber, which forces the flame and the hot products to be pushed out into the main chamber, igniting the main charge through a complex coupling of fluid mechanics, thermal effects and chemical kinetics. Depending on the pre-chamber mixture composition and the duct sizes, the flame entering the main chamber can be quenched or not [4, 4]. Furthermore, the hot products can result from complete or incomplete combustion. In the last case, the presence of highly reactive radicals may directly promote chain branching reactions and thus ignition.

A few academic configurations have been used to study pre-chamber jet ignition mechanisms. Yamaguchi et al. 44] experimentally studied ignition and burning processes in a divided chamber bomb. Depending on the duct size, which was found to have a major effect on the jet structure, four ignition and burning patterns were identified: "I, chemical chain ignition and well dispersed burning; II, composite ignition and well-dispersed burning followed by wrinkled laminar burning; III, flame kernel torch ignition and wrinkled laminar burning; IV, flame front torch ignition and wrinkled laminar burning". This study was the first to provide details on the different jet structures and combustion patterns. More recently, Biswas et al. 4] experimentally confirmed that the pre-chamber flame can be quenched due to heat loss and/or high stretch rate while combustion products still ignite the main chamber. This mechanism is called jet ignition in opposition to the mechanism of flame ignition, which simply involves a jet of wrinkled turbulent flames. Fei et al. 11] computationally studied ignition mechanisms using Direct 
Numerical Simulation (DNS) in a simplified constant volume divided chambers system. Interaction between pre- and main chambers was precisely described. The processes governing ignition and flame propagation were also highlighted. The chemical effect of the pre-chamber jet on the combustion in the main chamber was examined: it was found that combustion in the pre-chamber affects the combustion in the main chamber by providing radicals and combustion intermediates and by enriching the lean mixture in the main chamber due to unburned fuel coming from the pre-chamber. These academic studies are essential to build a substantial knowledge on pre-chamber ignition behaviour. The question then arises: how does pre-chamber ignition behave in a real engine?

In this study, Large Eddy Simulation (LES) is used as a tool to investigate pre-chamber ignition system behaviour in a real ICE configuration, where:

- the spark Ignition Timing (IT) has a crucial effect on pre-chamber ignition and flame propagation;

- the aerodynamic flow created during the compression phase affects combustion in both chambers;

- the piston motion directly impacts the pressure difference between the two chambers.

Only an LES of a full engine can address these issues correctly. From a numerical point of view, this involves multiple challenges:

- The flame issuing from the ducts connecting the two chambers may be quenched because of flame/wall interaction so that an healthy active flame may actually never enter the main chamber. Heat losses to the walls must then be correctly predicted.

- If no flame kernel enters the main chamber, the hot jet may not ignite the main chamber right away [44,4] but may still be able to induce ignition later: pre-chamber products can enter the main chamber as a jet entraining the surrounding fluid, mix with the fresh premixed gases and eventually ignite the main chamber after a chemical ignition time. This suggests that a proper numerical description of these phenomena requires a sophisticated description of chemistry.

- The main chamber ignition involves mixing between turbulent jets of hot combustion products and compressed fresh premixed gases. This implies that, in addition to a reasonably complete description of chemistry, an advanced model for Turbulence-Chemistry Interaction (TCI) is also needed.

This paper shows that a massively parallel LES can be used to study all phases controlling the ignition of an ICE by a pre-chamber fed with a separated fuel injector. LES is used to simulate the compression and combustion phases of a single engine cycle at a single operating point. A Reynolds Averaged Navier-Stokes (RANS) simulation is used to produce an initial solution for the LES at Intake Valve Closing (IVC). First, pre-chamber filling by fresh mixture and fuel is investigated to analyze the flow and the fuel stratification in the pre-chamber. Then, aerothermochemical processes are studied to analyze the pre-chamber combustion, the flow through the ducts connecting the two chambers, the composition of the jets entering the main chamber and the ignition and combustion modes of the main chamber. 


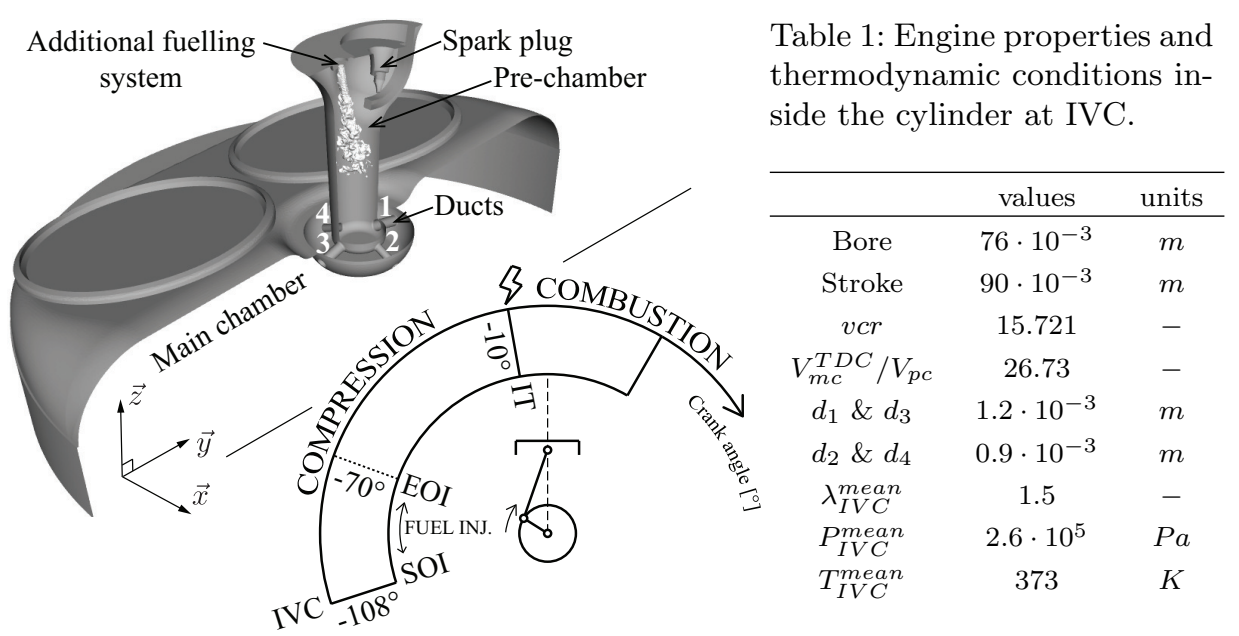

Fig. 1: Sketch of the simulated engine and timing diagram.

\section{Operating point}

Figure 1 shows a sketch of the simulated engine associated with its timing diagram. The pre-chamber has been designed to optimize filling and discharge [30. Table 1 shows geometric properties and thermodynamic conditions inside the cylinder of the turbocharged engine at IVC. $v c r$ is the volumetric compression ratio, $V_{p c}$ is the volume of the pre-chamber, $V_{m c}^{T D C}$ is the volume of the main chamber at Top Dead Centre (TDC), $d_{i}$ is the diameter of the duct $i$ (the 4 ducts do not have the same diameter). Walls are kept at a constant temperature of $420 \mathrm{~K}$ (specified by engine manufacturer). Propane is used as fuel for both intake lean premixed mixture and pre-chamber additional fuelling. Gaseous fuel injection inside the prechamber starts immediately after IVC at the beginning of the compression phase to avoid the requirement of high pressure injection which can lead to liquefaction.

\section{Chemistry description}

Because of the importance of chemistry in the process of ignition by hot products 11,1,44, using an accurate description of chemistry containing intermediate species is mandatory. Schemes derived from Analytically Reduced Chemistry (ARC) meet this need [13,12]. Here the ARC scheme is constructed using the YARC tool 32, which includes skeletal reduction and quasi-steady state approximation replacing transport equations of highly reactive species by analytical expressions of their concentrations. Hence, the number of transported species is reduced enabling such chemical schemes to be used for LES keeping the computational cost at an affordable level [23, 38, 13 .

Reduction process of the propane chemistry starts from the San Diego mechanism [35, 41, 34]. Since the work of Prince et al. 35, low temperature chemistry 


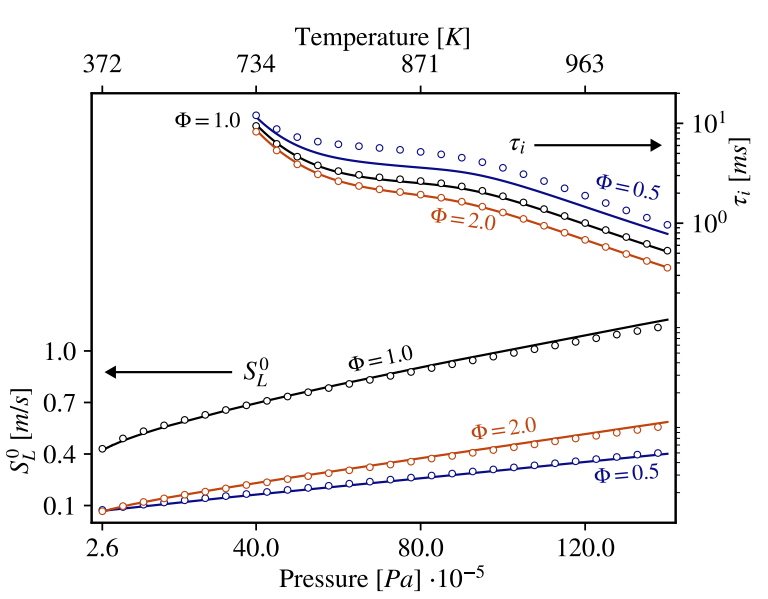

Fig. 2: Laminar flame speed $\left(S_{L}^{0}\right)$ and ignition time $\left(\tau_{i}\right)$ function of initial pressure, fresh gases temperature and fuel air equivalence ratio $\Phi$ for both the San Diego mechanism (-) and the ARC (o). Fresh gases follow an isentropic compression from mean pressure and temperature inside the engine at IVC.

is taken into account, enabling this mechanism to be used widely. Furthermore, it has been validated against scarce available experimental data 35,41, allowing us to take it as a reference.

For the reduction process, laminar one-dimensional flames and zerodimensional reactors are chosen as canonical cases in order to produce accuracypreserving targets (laminar flame speed $S_{L}^{0}$, ignition time $\tau_{i}$ as well as the evolution of $\mathrm{CO}, \mathrm{CO}_{2}, \mathrm{OH}$ species and heat release). The range of targeted operating conditions follows an isentropic compression from initial mean pressure and temperature inside the engine at IVC. Fuel air equivalence ratio $\Phi$ goes from 0.5 to 2.0. The final ARC scheme contains 32 species (11 of them in quasi-steady state) and 153 reactions. Figure 2 presents the evolution of the laminar flame speed and the ignition time over the range of operating conditions for both the San Diego mechanism and the ARC. The ARC scheme is in good agreement with the detailed one. Furthermore, the plateau of ignition time evolution is well reproduced, which demonstrates that both low and high temperature chemistries have been preserved during the reduction process.

\section{Turbulence-chemistry interaction model}

During flame propagation, the flame thickness of a premixed front in the conditions of the operating point considered here varies between 5 and $25 \mu \mathrm{m}$, so that a full DNS of this reactive flow is impossible. It is necessary to introduce a model for the interaction between turbulence and chemistry. The TCI model used here is the thickened flame model combined with an effiency function. It has been widely used for gas turbines [40, 18, 16], explosions [37, 43] and piston engines 10, 19. More precisely, TCI is modeled thanks to the dynamic formulation of the thickened flame model for LES [6]. The Charlette model [5] is used to take into account both the subgrid scale effects and the impact of flame thickening over flame wrinkling through an efficiency function based on direct numerical simulations. The efficiency function is estimated from an algebraic expression derived assuming an equilibrium between turbulence motions and flame front wrinkling. Input parameters such as laminar flame speed and flame thickness are tabulated 
before calculation and locally estimated as a function of local pressure, fresh gas temperature and equivalence ratio using atoms conservation and Bilger weighted definition for mixture fraction [3]. Such an estimation is mandatory because pressure, temperature and equivalence ratio are changing over space and time.

The flame sensor used for the dynamic formulation of the thickened flame model is based on the local value of heat release $\dot{\omega}_{T}$. As discussed in [27, during autoignition, the flame sensor can be triggered and inhibit the auto-ignition process by applying a thickening factor $F$ which increases diffusion and decreases species source terms. Thus, the flame sensor should only be triggered when a propagating flame is established. For that, following [27, a sensor with a threshold value based on the progress variable is build

$$
S=\frac{1}{4}\left[1-\tanh \left(K_{1}\left(\frac{\Omega_{0}-K_{2} \dot{\omega}_{T}}{\Omega_{0}}\right)\right)\right]\left[1-\tanh \left(K_{3}\left(c^{t h r}-c\right)\right)\right],
$$

where $K_{i}$ are positive constant parameters, $\Omega_{0}$ is the laminar flame maximum heat release, $c^{t h r}$ the progress variable threshold value parameter and $c$ the progress variable based on $\mathrm{CO}$ and $\mathrm{CO}_{2}$ mass fraction

$$
c=\frac{Y_{\mathrm{CO}}+Y_{\mathrm{CO}_{2}}}{\left(Y_{\mathrm{CO}}+Y_{\mathrm{CO}_{2}}\right)^{e q}},
$$

where ${ }^{e q}$ stand for equilibrium value. $Y_{k}^{e q}$ and $\Omega_{0}$ are tabulated before calculation and locally estimated. $S$ is not triggered when $c<c^{t h r}$ which allows not to alter the auto-ignition process before completion and transition to a propagating flame.

\section{Numerical setup}

The solver used for the present LES is an explicit cell-vertex massively-parallel code solving the compressible multi-species Navier-Stokes equations called AVBP 42,17. To solve the LES equations over the unstructured mesh, a fully explicit two step Taylor-Galerkin numerical scheme is used [7] which offers third order accuracy in space and time on arbitrary unstructured meshes. Full description of filtered LES equations can be found in 18 . Filtered viscous terms are modeled via a gradient assumption, species diffusion fluxes rely on Hirschfelder and Curtis approximation 20. Species Schmidt numbers are constant but non-equal for each species. Prandtl number is assumed to be constant. Subgrid scale diffusive heat and species fluxes are modeled with constant Prandtl and Schmidt turbulent numbers. Viscosity follows a power law function of temperature. The effects of unresolved small-scale fluid motions are modelled using the WALE 31 subgrid-scale model. Wall boundary layer behaviour is modelled with a classical linear or logarithmic law of the wall depending on the value of the dimensionless variable for wall-distance $y^{+}$. Pre-chamber spark ignition is modeled thanks to the energy deposition model [24] which distributes energy inside a sphere of radius $1.5 \mathrm{~mm}$.

\subsection{Mesh characteristics}

Different meshes are used to compute the whole simulation. All these meshes are body fitted and match perfectly the engine geometry. The number of elements 


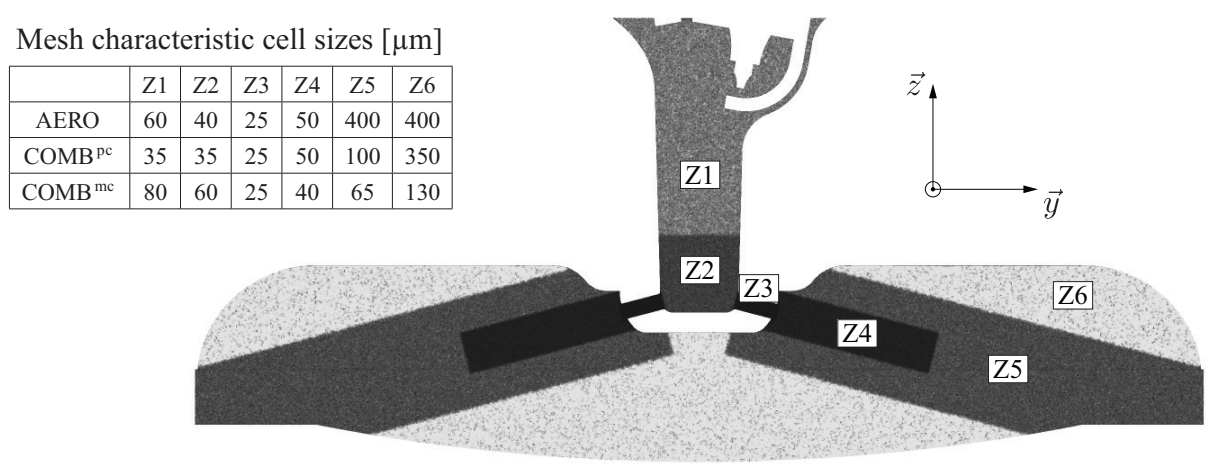

Fig. 3: Overview of the computational domain using a plane cut normal to the $\mathbf{x}$ axis, intersecting duct 1 and 3 by their axis. Different mesh zones Z1 to Z6 are defined with different characteristic cell sizes.

and the resolution of each of these meshes vary strongly during the simulation according to the piston position and the physics considered. Figure 3 shows a detailed view of the computational domain as well as the characteristic cell sizes used. Six mesh zones $\mathrm{Z} 1$ to $\mathrm{Z} 6$ are considered whose resolution changes according to three grid setups: AERO, $\mathrm{COMB}^{\mathrm{pc}}$ and $\mathrm{COMB}^{\mathrm{mc}}$.

- The AERO grid setup is used before pre-chamber spark ignition. During this phase, a good resolution of the flow and turbulence inside the pre-chamber is required (mesh zones $\mathrm{Z} 1$ and $\mathrm{Z} 2$ ). A fine resolution of the main chamber is not needed and only the biggest eddies are resolved in the mesh zones Z5 and Z6.

- The $\mathrm{COMB}^{\mathrm{pc}}$ grid setup is used from pre-chamber spark ignition to prechamber hot gases ejection. The pre-chamber zones Z1 and Z2 are refined to reduce the impact of the models on the flame development. The resolution in the main chamber zones $\mathrm{Z} 4$ to $\mathrm{Z} 6$ are also increased to allow an accurate description of the turbulent jets coming from the pre-chamber.

- The COMB ${ }^{\mathrm{mc}}$ grid setup is used during the ignition and the combustion of the main chamber. The mesh resolution is reduced in the pre-chamber and increased in the main chamber, especially in the zones Z4 and Z5 where the mechanism of jet ignition is expected to happen.

The mesh zone Z3 has a constant fine resolution to allow a precise description of the flow in the ducts throughout the simulation: 48 and 36 points are used to discretize the diameter of the ducts 1 and $3(1.2 \mathrm{~mm})$ and the ducts 2 and $4(0.9$ $\mathrm{mm}$ ), respectively. During the whole simulation, the dimensionless wall-distance $y^{+}$reaches a maximum value of 150 wall units in the ducts. This ensures that the law-of-the-wall remains in its domain of validity as needed for a correct evaluation of pressure losses between the pre- and main chambers. The meshes contain from 50 to 300 million cells depending on the piston position and the grid setup. The number of cells as a function of Crank Angle Degree (CAD) is displayed in Fig. 4. 
5.2 Moving mesh and automatic remeshing

During the whole simulation, valves are fixed in closed position but the piston is moving: the resolution of the Navier-Stokes equations on a moving mesh is achieved using the Arbitrary Lagrangian Eulerian (ALE) method [21. Numerical schemes are written in order to take into account displacement and deformation of cells. To preserve a high accuracy, the LES is stopped when the cell distorsion is considered too high [28] and the solution is remapped onto a new cleaner mesh, conserving characteristic cell sizes (Fig. 3). This is done fourteen times during the simulation, using remeshing and interpolation 29] which are performed automatically thanks to the Mmg remeshing library [8]. Figure 5 shows the computational costs of the simulation: the additional computational cost associated with automatic remeshing is negligible.

\subsection{High performance computing}

The simulation is performed using 3600 to 7200 Message Passing Interface (MPI) tasks on the Iren ${ }^{1}$ BullSequana X1000 supercomputer. It is equipped with 1656 Intel Skylake 8168 bi-processors nodes at 2,7 GHz. Each processor consists of 24 cores and 192 GB of DDR4 memory per node. All processors are connected via an InfiniBand EDR interconnect.

In order to reduce the computational cost, the AERO computation is done using only 5 species: $\mathrm{C}_{3} \mathrm{H}_{8}, \mathrm{O}_{2}, \mathrm{~N}_{2}, \mathrm{CO}_{2}$ and $\mathrm{H}_{2} \mathrm{O}$, without solving chemistry reactions. This is allowed by the condition of pressure and temperature which exclude auto-ignition events during this simulation phase. The chemical composition is thus frozen. Thanks to this strategy combined with a relative low number of cells, the AERO computation accounts for only $6 \%$ of the total computational cost despite its comparatively long duration (Fig. 5). The combustion phases $\mathrm{COMB}^{\mathrm{pc}}$ and $\mathrm{COMB}^{\mathrm{mc}}$ are the major contributors to the computational cost. Figure 4 shows the evolution of the reduced efficiency, defined as

$$
\operatorname{red}^{\text {eff }}=\frac{n_{\text {cores }} \cdot t_{\text {elapsed }}}{n_{\text {it }} \cdot n_{\text {cell }} \cdot n_{\text {eq }}}
$$

where $n_{\text {cores }}$ is the number of cores used, $t_{\text {elapsed }}$ is the time elapsed during the computation, $n_{i t}$ is the number of iterations, $n_{\text {cell }}$ is the number of cells and $n_{e q}$ is the number of equations included in the system of Navier-Stokes equations solved. This index measures the efficiency of the computation and should not change with increasing $n_{\text {cell }}$ and $n_{e q}$. The maximum variation from the average value is of the order of $10 \%$ during each of the three simulation phases. The low deviation of red $^{\text {eff }}$ during these simulation phases shows the good behaviour of the numerical solver, as $n_{\text {cell }}$ changes over time. The increase of red $d^{e f f}$ between AERO and COMB computations is due to the computation of the chemical reactions and the TCI model.

\footnotetext{
1 http://www-hpc.cea.fr/en/complexe/tgcc-Irene.htm
} 


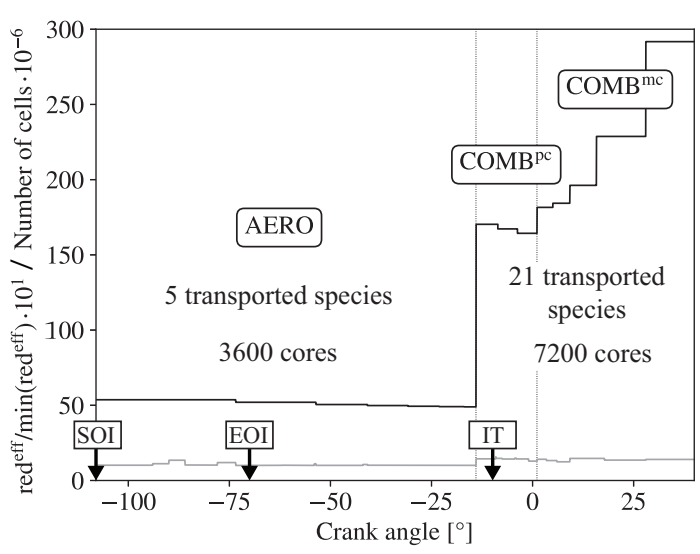

Fig. 4: Evolution of the number of cells (-) and reduced efficiency (-) during the simulation.

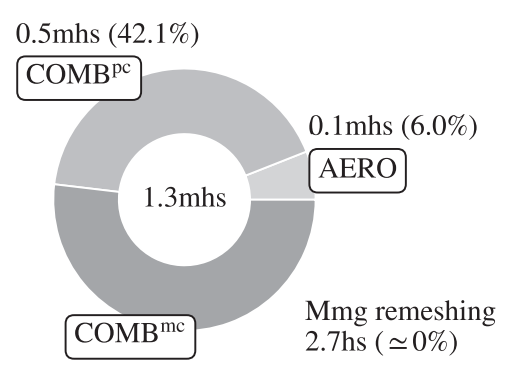

$0.7 \mathrm{mhs}(51.9 \%)$

Fig. 5: Computational cost of the simulation phases and remeshing $(\mathrm{mhs}=$ millions hours, hs $=$ hours).

\section{Pre-chamber filling during compression phase}

This section describes the LES results from IVC (-108 CAD) to pre-chamber spark IT (-10 CAD). During this phase, the piston moves up and the pre-chamber is filled by fresh gases coming from the main chamber at an air fuel equivalence ratio of $\lambda=1.5$. In addition, from the Start Of Injection (SOI) (-108 CAD) to the End Of Injection (EOI) (-70 CAD), the additional fuelling system (Fig. 1) adds pure fuel to achieve a near stoichiometric mixture inside the pre-chamber at IT.

Figure 6 shows the evolution of mixture characteristics inside the pre-chamber during the compression phase. The global air fuel equivalence ratio of the prechamber $\lambda^{p c}$ (based on the mass of oxidizer and fuel trapped inside the prechamber) significantly decreases during pure fuel injection, then increases because of dilution by fresh gases coming from the main chamber to reach $\lambda^{p c} \simeq 1$ at IT ($10 \mathrm{CAD}$ ). Even if the target of a stoichiometric pre-chamber is reached on average, the standard deviation of $\lambda$ predicted by the LES inside the pre-chamber shows high values which means high segregation of the mixture. Figure 7 illustrates this segregation: the rich mixture is located at the top of the pre-chamber, pushed and confined by the flow of fresh gases coming from the main chamber with limited mixing. At $-10.5 \mathrm{CAD}$, just before spark IT, $\lambda$ goes from 1.5 in the flow coming from the main chamber to 0.4 in the interstices between the ground electrode and the main chamber, where mixing is poor. Rich pockets may not burn, lead to slow combustion and produce pollutant emissions. To better quantify the mixture composition at the location of spark ignition, the air fuel equivalence ratio inside a sphere of radius $2 \mathrm{~mm}$ located at ignition center $\lambda^{i}$ is plotted over time in Fig. 6 . $\lambda^{i}$ reaches an air fuel equivalence ratio around 0.75 before ignition, which means that spark ignition takes place in a rich but flammable mixture.

Figure 6 also shows the evolution of the mass fraction of residuals gases trapped inside the pre-chamber $Y_{R}^{p c}$. At IVC (-108 CAD), residuals inside the pre-chamber are already diluted $\left(Y_{R}^{p c} \simeq 0.4\right)$ which shows that the intake phase plays a role in the pre-chamber filling. During the compression phase, $Y_{R}^{p c}$ significantly decreases 


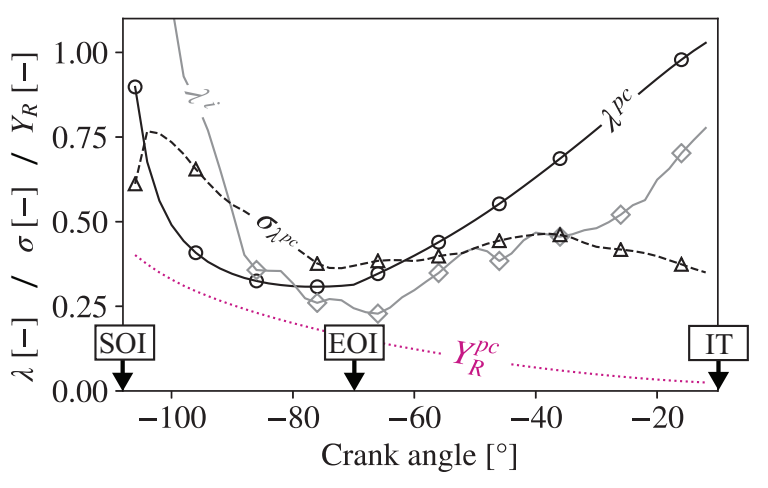

Fig. 6: Air fuel equivalence ratio inside the pre-chamber $\lambda^{p c}$ and inside sphere of radius $2 \mathrm{~mm}$ located at ignition center $\lambda^{i}$. Standard deviation of air fuel equivalence ratio $\sigma_{\lambda^{p c}}$ and residuals mass fraction $Y_{R}^{p c}$ inside the prechamber.

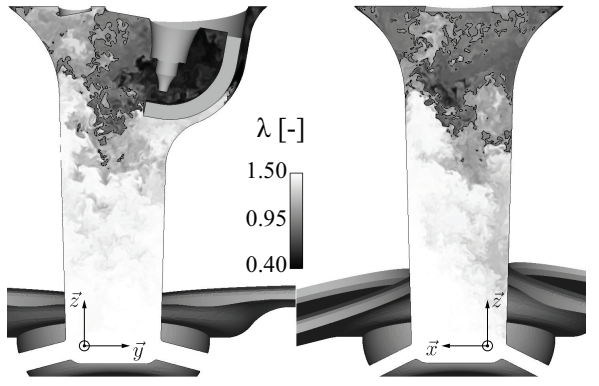

Fig. 7: Plane cut normal to the $\mathbf{x}$ axis (left), $\mathbf{y}$ axis (right) intersecting the ducts by their axis at $-10.5 \mathrm{CAD}$ coloured by the air fuel equivalence ratio $\lambda$ with an iso-contour of stoichiometric equivalence ratio $(-)$.

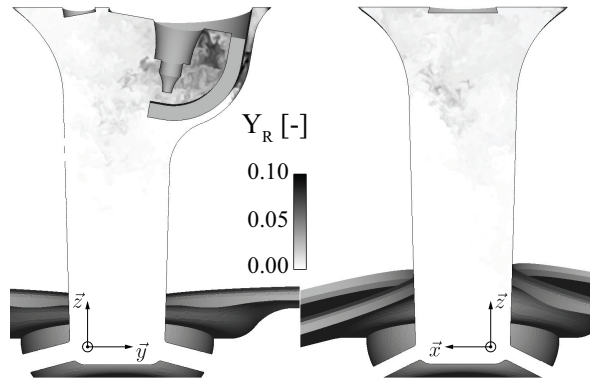

Fig. 8: Plane cut normal to the $\mathbf{x}$ axis (left), y axis (right) intersecting the ducts by their axis at -10.5 CAD coloured by the residuals mass fraction $Y_{R}$.

to reach $Y_{R}^{p c} \simeq 0.025$ just before spark IT $(-10 \mathrm{CAD})$ : the mass of residuals is negligible in comparison with the mass of fresh gases. Figure 8 shows the field of residuals mass fraction $Y_{R}$ inside the pre-chamber at $-10.5 \mathrm{CAD}$, just before spark IT. Regions of high $Y_{R}$ can inhibit combustion and are located between the interstices created by the spark plug, where the mixture is also very rich because of the poor mixing.

The analysis of the field of equivalence ratio and residuals inside the prechamber leads to a common conclusion: for the present design, mixing could be significantly improved to produce a more homogeneous charge inside the pre-chamber and dilute residuals. This can be achieved by reducing crevices and creating a special flow pattern.

\section{Aerothermochemistry processes during combustion phase}

This section describes the LES results obtained for the combustion phase from the pre-chamber spark ignition (-10 CAD) to the full consumption of the charge. 


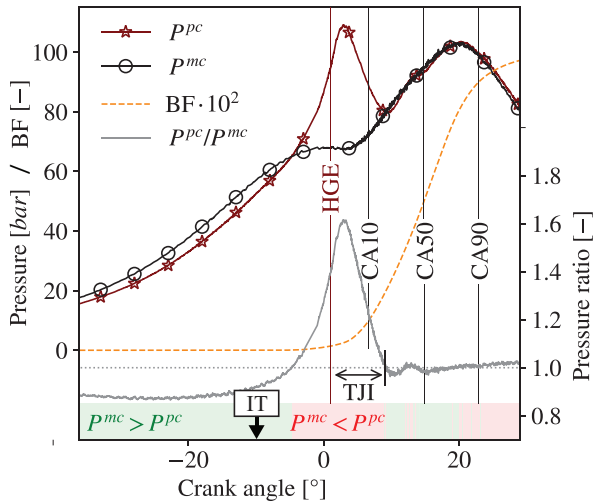

Fig. 9: Evolution of main and prechamber pressure, pre- over main chamber pressure ratio and global BF.

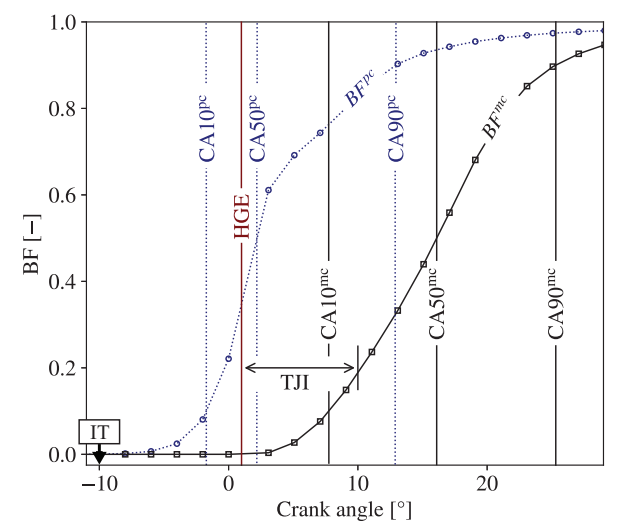

Fig. 10: Evolution of local BF inside pre $\left(\mathrm{BF}^{\mathrm{pc}}\right)$ and main chamber $\left(\mathrm{BF}^{\mathrm{mc}}\right)$.

\subsection{Global behaviour}

Figure 9 shows the pressure evolution inside the pre- and main chambers, as well as the pressure ratio between the two chambers, the global Burnt Fraction (BF) and the CAx which represent the crank angle at which $\mathrm{x} \%$ of the amount of fuel available have been burnt (i.e. $\mathrm{BF}=\mathrm{x} \%$ ). Local $\mathrm{BF}$ and $\mathrm{CAx}$ inside pre-chamber and main chamber are shown in Fig. 10 After chemical run away time and kernel growth, $10 \%$ of the available charge inside the pre-chamber has been burnt at -1.7 CAD. Because of combustion inside a semi-confined small volume, the pressure in the pre-chamber increases quickly: first, the flame consumption speed increases with isentropic compression of fresh gases; second, fresh gases are pushed out of the pre-chamber through the ducts. These two phenomena produce a fast increase of $\mathrm{BF}^{\mathrm{pc}}$ until approximatively $\mathrm{CA} 50^{\mathrm{pc}}$. Later, the pre-chamber combustion suffers from near wall combustion and heat losses inside the small volume as well as local rich mixture combustion due to mixture segregation which slows down the $\mathrm{BF}^{\mathrm{pc}}$ growth. The pressure ratio between the chambers reaches a maximum value of 1.61 which produces vigorous turbulent jets. 11 CAD after spark IT, the first hot gases cross the ducts and enter the main chamber: Hot Gases Ejection (HGE) happens around 1 CAD. Turbulent jets of hot products successfully ignite the main chamber and $10 \%$ and $90 \%$ of the available charge inside the main chamber is burnt at 7.7 and 25.3 CAD, respectively. This demonstrates that lean mixtures can be burnt within a short time using such pre-chamber ignition system, as expected for this device.

\subsection{Jets properties}

Figures 11 and 12 show ducts characteristic quantities integrated through a surface (illustrated in Fig. 11) normal to the ducts, located at the outlet (main chamber side). Figure 11 displays aerodynamics properties while Fig. 12 focuses on mixture 
composition. Any variable $\xi$ surface mean reads

$$
\langle\xi\rangle=\frac{1}{S} \iint_{S} \xi d S
$$

where $S$ is the surface of integration. The total enthalpy flow in Fig. 11 is defined as

$$
\dot{H}_{t}=\iint_{S} \rho h_{t} \mathbf{u} \cdot \mathbf{n}_{\mathbf{S}} d S
$$

where $\rho$ is the density, $h_{t}$ is the total enthalpy per unit mass, $\mathbf{u}$ is the flow speed, $\mathbf{n}_{\mathbf{S}}$ is the normal to the surface $S$. The Reynolds number Re is calculated using surface mean values of density $\rho$, normal speed $U_{n}$ and temperature $T$ for viscosity calculation. Jet Reynolds numbers reach values up to $10^{5}$ during fresh gases ejection and quickly fall during hot gases ejection due to the increase in viscosity. However, all jets remain turbulent. Although the pressure ratio between the chambers reaches high values up to 1.6 (Fig. 9), it does not reach the theoretical critical choked pressure ratio of 1.85 estimated with a constant heat capacity ratio $\gamma=1.33$ and no shock is observed: surface mean normal Mach numbers reach values up to 0.75 while normal speeds go over $600 \mathrm{~m} / \mathrm{s}$. Turbulent Jet Ignition (TJI) starts when the first pre-chamber hot gases penetrate the main chamber (HGE) and ends when the pressure ratio between the two chambers becomes unity (mass flow becomes zero). TJI duration is about 9 CAD (Fig. 11). The total enthalpy flow reaches values up to $23 \mathrm{~kW}$ for the two bigger ducts and $12 \mathrm{~kW}$ for the smaller ones. This is a huge flow of energy in comparison with a classical spark plug. For example, a classical spark plug with a nominal electrical energy of 100 $m J$ and an overall duration of $400 \mu s$ produces an overall theoretical transfer of energy to the mixture of $0.25 \mathrm{~kW}$, without taking into account conductive and radiative losses. Figure 12 reveals that the composition of the hot gases produced by the pre-chamber to ignite the main chamber varies considerably during the TJI process. An intermediates mass fraction can be introduced to analyze the mixture composition:

$$
Y_{I}=1-\left(Y_{C_{3} H_{8}}+Y_{O_{2}}+Y_{C_{2}}+Y_{H_{2} O}+Y_{N_{2}}\right) .
$$

The composition of the hot gases jets during TJI can be divided in three parts (Fig. 12, whose exact limits are dependent on the duct considered:

1. Intermediate products of lean combustion (due to the pre-chamber flame) are exhausted through the ducts between approximatively 1 and $4 \mathrm{CAD}$ where $0.1<\langle c\rangle<0.9$. Even if there is a mean stoichiometric mixture inside the prechamber, the first hot products to be exhausted, are produced by combustion of the lean gases initially present in the main chamber which flowed through the ducts during the compression phase. It follows a simple rule: the last gases to be entered in the pre-chamber are the first to be ejected and they control the initiation of the combustion in the main chamber.

2. Complete products of lean combustion are exhausted from approximatively 4 to $7 \mathrm{CAD}$. The mass fraction of intermediate species is very small compared to the other phases.

3. Incomplete products of rich combustion previously trapped in the upper part of the pre-chamber are then exhausted through the ducts except for duct 4. These incomplete combustion products cause an increase in the intermediates mass fraction $Y_{I}$ of the exhausted gases. 

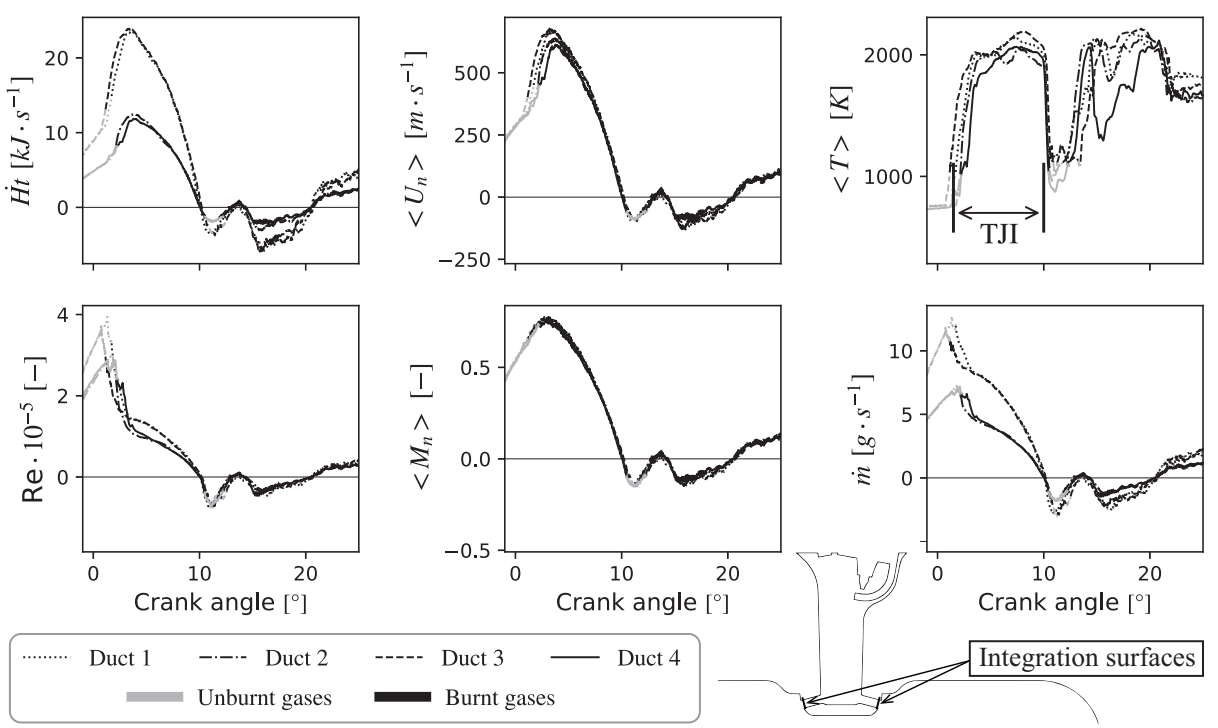

Fig. 11: Evolution of total enthalpy flow, mean normal speed, surface mean temperature, Reynolds number, mean normal Mach number and mass flow through the outlet of the ducts. Sketch of the integration surfaces used to compute the quantities (bottom right).

When the main chamber pressure becomes higher than the pre-chamber pressure at 10 CAD (Fig. 9), back-flow occurs: TJI ends. The lean main chamber mixture composed of flame kernels is convected back into the pre-chamber which contains hot products of incomplete combustion. The mixing of the lean main chamber mixture which includes $\mathrm{O}_{2}$ in excess with the hot incomplete rich combustion products creates vigorous reactions able to reverse the flow for a short while. However, the combustion in the main chamber is still going on and leads to flow reversal (around 14 CAD) until combustion weakens and mechanical expansion through piston movement makes pressure in the main chamber always lower than in the pre-chamber.

Figure 13 shows differences of surface mean temperature $\Delta_{T}$ between two integration surfaces located at the inlet and at the outlet of each duct during TJI. $\Delta_{T}$ measures the cooling of the pre-chamber gases during their flow through the cooled wall ducts. $\Delta_{T}$ presents fluctuation at the beginning of TJI process because of the heterogeneities of the crossing mixture composed of both pockets of burn gases and fresh gases that flow intermittently through the ducts. Later, from 4 to $8 \mathrm{CAD}$, the temperature drop through the ducts seems to be stabilized around $140 \mathrm{~K}$ for the bigger ducts and $175 \mathrm{~K}$ for the smaller ones. $\Delta_{T}$ goes down as the mass flow tends to zero $\left(\Delta_{T} \propto \dot{m}^{-1}\right)$ before back flow occurs and TJI ends.

\subsection{Main chamber ignition}

Before HGE, the fresh gases turbulent jets produced by the pre-chamber act as a turbulence source for the main chamber. Then, burnt gases reach the exhaust 

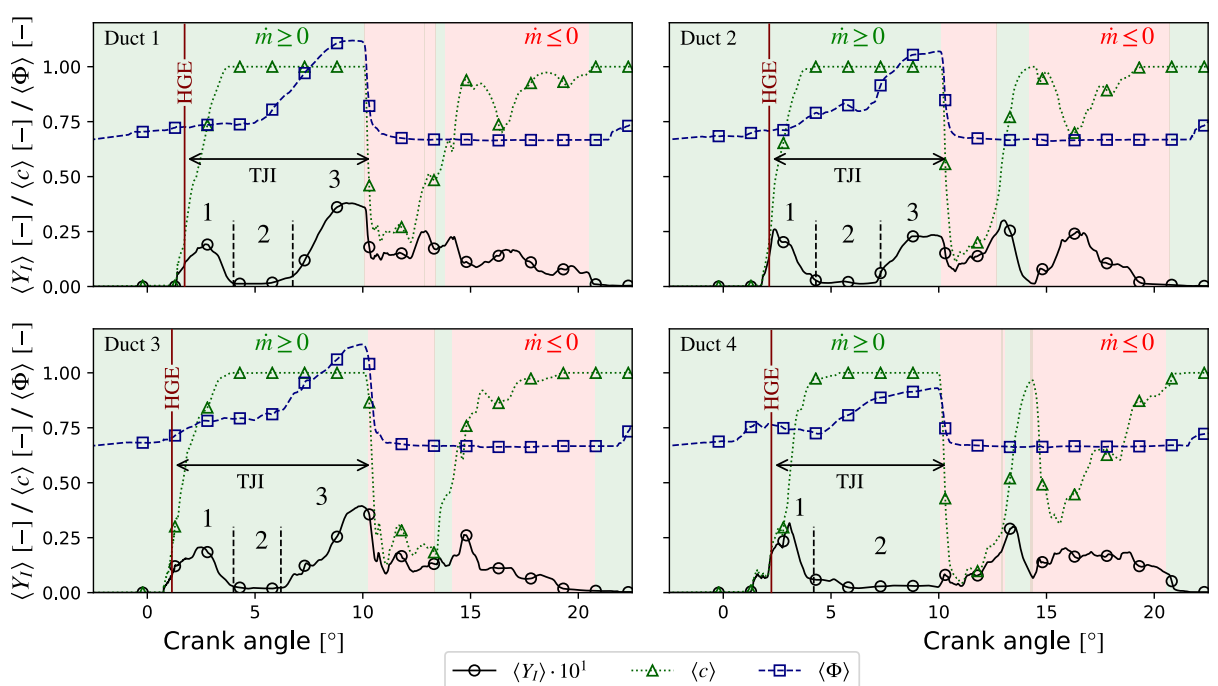

Fig. 12: Surface mean species mass fraction, progress variable and fuel air equivalence ratio of the mixture flowing through the ducts.

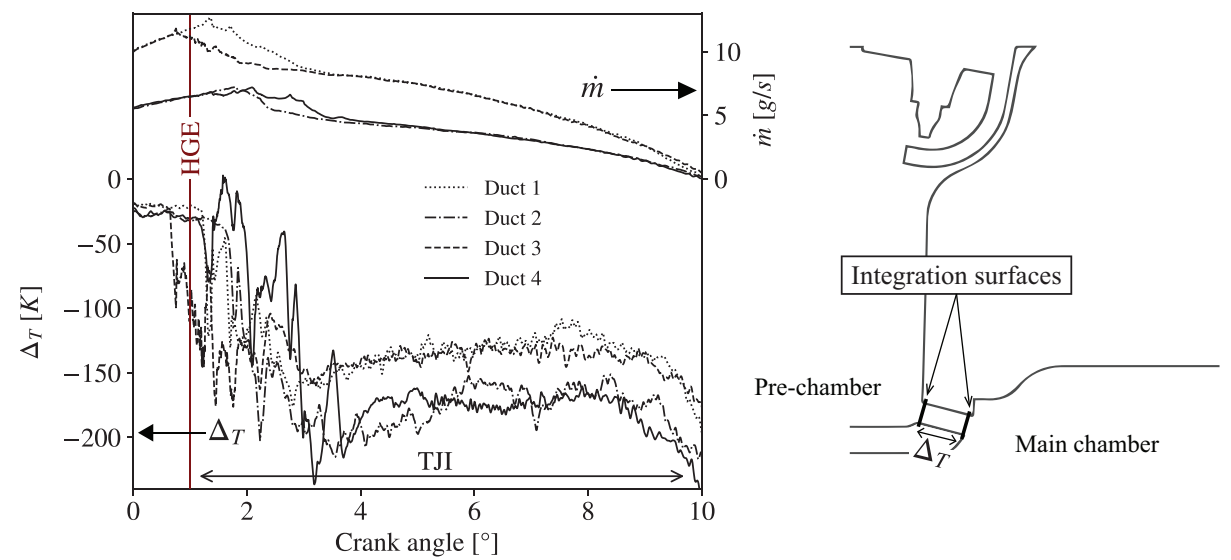

Fig. 13: Evolution of temperature difference between inlet and outlet of the ducts next to mass flow through the ducts (left). Sketch of the integration surfaces used to compute $\Delta_{T}$ (right).

of the ducts and hot products turbulent jets act as both an ignition and a turbulence source. Once the main chamber has been ignited, jets sustain combustion until pressure equilibrium between the two chambers. Figure 14 shows the flame topology through a plane cut coloured by the heat release $\dot{\omega}_{T}$ for three depicted sequences of the TJI process:

- Ignition by Hot Gases ejection (IHG): pre-chamber products enter the main chamber. Close to the nozzle of the ducts, heat release is scarce due to a combination of local stretch and temperature drop through wall heat losses and 
expansion between pre- and main chambers. Because of the high turbulence intensity, mixing is fast, hot products are quickly diluted into the surrounding lean fresh mixture and the overall reaction rate is mainly limited by chemistry. Inner intense mixing regions are chemically active downstream of the jets. No flamelet structure is observed.

- Combustion Sustained by Hot Gases ejection (CSHG): flames begin to organize as fronts while jets still sustain combustion by providing more hot products and turbulence sources until the pressure difference between the two chambers becomes negligible. Iso-contours of temperature become parallel suggesting that a flamelet regime is developing in most of the chamber.

- Combustion Unsustained by Hot Gases ejection (CUHG): wrinkled flames sweep across the remaining space, consuming the fresh main chamber gases without significant effect of the weakened hot product jets. Flamelets are observed almost everywhere.

This ignition sequence corresponds very well to the combustion patterns II experimentally established by Yamaguchi et al. 44, where a composite ignition due to a combined effect of chemical chain branching reactions and flame kernels happens followed by wrinkled flames.

Figure 15 shows a qualitative estimation of the combustion regime which takes place inside the main chamber during combustion using the diagram proposed by Peters $33 . l_{t}$ is the integral length scale approximated using an empirical relation suggested by Lumley 26 ]

$$
l_{t}=h_{c} / 6
$$

where $h_{c}$ is the clearance height. $u_{t}^{\prime}$ is the fluctuation speed at length scale $l_{t}$ estimated assuming a Kolmogorov cascade

$$
u_{t}^{\prime}=\hat{u}^{\prime}\left(l_{t} / \hat{\Delta}\right)^{1 / 3},
$$

with $\hat{u}^{\prime}$ is the fluctuation speed at the filter scale $\hat{\Delta}$ extracted from the LES using an operator derived by Colin et al. [6]. Each marker corresponds to space-averaged values along the flame front $(c=0.3 \pm 0.05)$ inside the main chamber. This low value of progress variable is used to minimize the bias due to increased viscosity and density across the flame. As observed in Fig. 14. combustion seems to begin in a thickened-wrinkled flame regime and tends to go towards wrinkled flamelets as $u_{t}^{\prime}$ decreases with time.

\section{Conclusion}

This work has shown that it was possible to perform a high-fidelity, body fitted, chemically accurate LES of pre-chamber ignition in a real ICE configuration. It includes pre-chamber filling and combustion phases. According to the physical and chemical characteristics of the jets, the ignition and burning processes occurring inside the main chamber have been identified, clarified and linked with academic studies of TJI. More generally, results confirm the power of high-fidelity LES coupled to accurate chemistry description, precise TCI models and massively parallel codes to analyze phenomena controlling pre-chamber ignition in realistic engine geometries. 

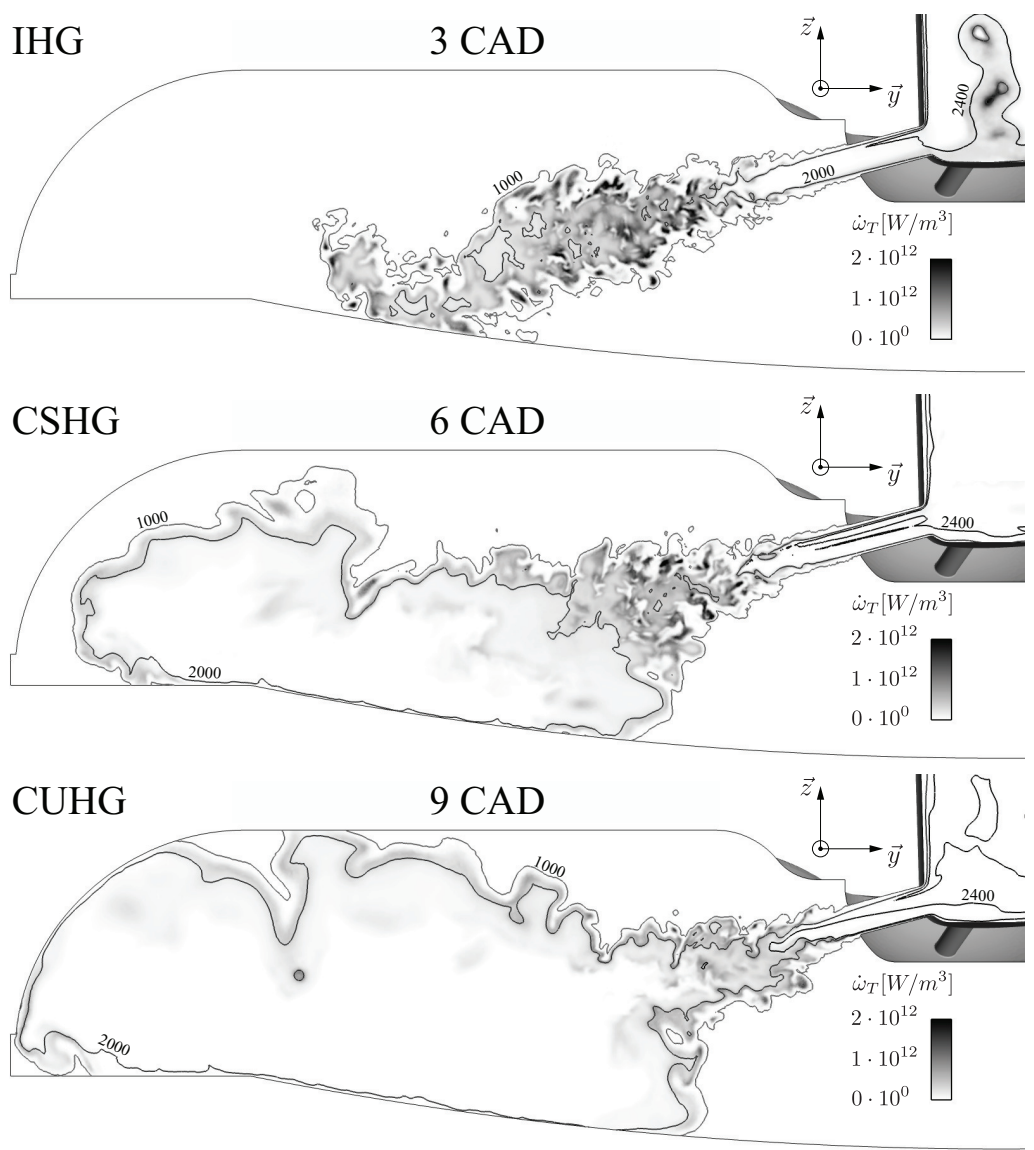

Fig. 14: Plane cut normal to the $\mathbf{x}$ axis, intersecting the duct 3 by its axis and coloured by the heat release with three iso-contours of temperature for the three depicted sequences of the TJI process.

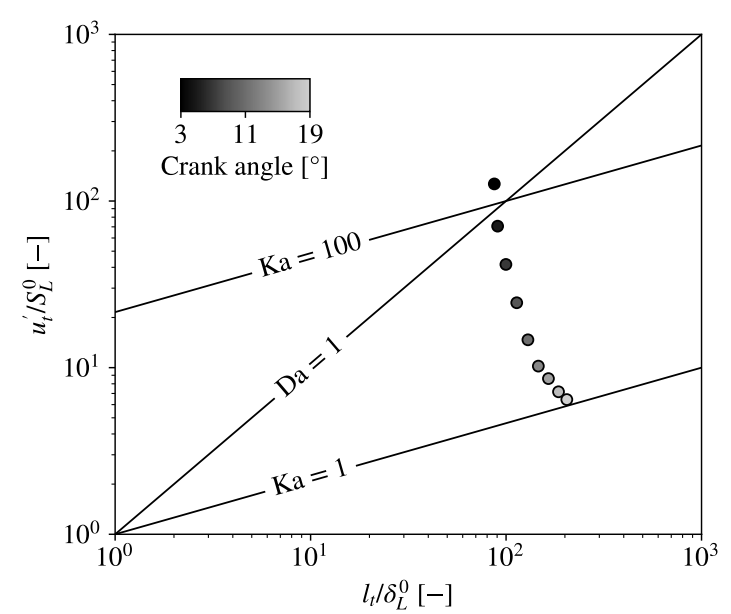

Fig. 15: Qualitative estimation of the combustion regime during the main chamber combustion using diagram proposed by Peters 33. Length and velocity ratios are conditional mean values for $c=0.3 \pm 0.05$ inside the main chamber. 
Acknowledgements This work was granted access to the High Performance Computing (HPC) resources of "Très Grand Centre de calcul du Commissariat à l'énergie atomique et aux énergies alternatives (TGCC)" under the "Grand Challenge" allocation number gch0301 attributed by "Grand Équipement National de Calcul Intensif (GENCI)". The authors thank the partners of the Efficient Additivated Gasoline Lean Engine (EAGLE) project funded by the European Union's Horizon 2020 research and innovation programme under the grant agreement number 724084 for the release of the pre-chamber design.

Funding Quentin Malé is the recipient of a "Conventions Industrielles de Formation par la Recherche (CIFRE)" Ph.D. research fellowship number 2017/0295.

Conflict of interest The authors declare that they have no conflict of interest.

\section{References}

1. Allison, P.M., de Oliveira, M., Giusti, A., Mastorakos, E.: Pre-chamber ignition mechanism: Experiments and simulations on turbulent jet flame structure. Fuel 230, 274-281 (2018)

2. Attard, W.P., Toulson, E., Huisjen, A., Chen, X., Zhu, G., Schock, H.: 2. SAE Technical Paper (2012)

3. Bilger, R.W.: The structure of turbulent nonpremixed flames. Symposium (International) on Combustion 22(1), 475-488 (1989)

4. Biswas, S., Tanvir, S., Wang, H., Qiao, L.: On ignition mechanisms of premixed CH4/air and H2/air using a hot turbulent jet generated by pre-chamber combustion. Applied Thermal Engineering 106, 925-937 (2016)

5. Charlette, F., Meneveau, C., Veynante, D.: A power-law flame wrinkling model for LES of premixed turbulent combustion Part I: non-dynamic formulation and initial tests. Combustion and Flame 131(1-2), 159-180 (2002)

6. Colin, O., Ducros, F., Veynante, D., Poinsot, T.: A thickened flame model for large eddy simulations of turbulent premixed combustion. Physics of Fluids 12(7), 1843-1863 (2000)

7. Colin, O., Rudgyard, M.: Development of High-Order Taylor-Galerkin Schemes for LES. Journal of Computational Physics 162(2), 338-371 (2000)

8. Dapogny, C., Dobrzynski, C., Frey, P.: Three-dimensional adaptive domain remeshing, implicit domain meshing, and applications to free and moving boundary problems. Journal of Computational Physics 262, 358-378 (2014)

9. Dunn-Rankin, D., Therkelsen, P. (eds.): Lean Combustion - Technology and Control, 2nd edn. Academic Press (2016)

10. Enaux, B., Granet, V., Vermorel, O., Lacour, C., Pera, C., Angelberger, C., Poinsot, T.: LES study of cycle-to-cycle variations in a spark ignition engine. Proceedings of the Combustion Institute 33(2), 3115-3122 (2011)

11. Fei, Q., Shah, A., Zhi-wei, H., Li-na, P., Tunestal, P., Xue-Song, B.: Detailed numerical simulation of transient mixing and combustion of premixed methane/air mixtures in a pre-chamber/main-chamber system relevant to internal combustion engines. Combustion and Flame 188, 357-366 (2018)

12. Felden, A., Esclapez, L., Riber, E., Cuenot, B., Wang, H.: Including real fuel chemistry in LES of turbulent spray combustion. Combustion and Flame 193, 397-416 (2018)

13. Felden, A., Riber, E., Cuenot, B.: Impact of direct integration of Analytically Reduced Chemistry in LES of a sooting swirled non-premixed combustor. Combustion and Flame 191, 270-286 (2018)

14. Filho, F.A.R., Baêta, J.G.C., Teixeira, A.F., Valle, R.M., de Souza, J.L.F.: E25 stratified torch ignition engine emissions and combustion analysis. Energy Conversion and Management 121, 251-271 (2016)

15. Filho, F.A.R., Teixeira, A.F., Rodrigues da Costa, R.B., Baêta, J.G.C., Valle, R.M.: Stratified Torch Ignition Engine: Performance Analysis. SAE Technical Paper (2016)

16. Ghani, A., Poinsot, T., Gicquel, L., Staffelbach, G.: LES of longitudinal and transverse self-excited combustion instabilities in a bluff-body stabilized turbulent premixed flame. Combustion and Flame 162(11), 4075-4083 (2015) 
17. Gicquel, L.Y.M., Gourdain, N., Boussuge, J.F., Deniau, H., Staffelbach, G., Wolf, P., Poinsot, T.: High performance parallel computing of flows in complex geometries. Comptes Rendus Mecanique 339(2-3), 104-124 (2011)

18. Gicquel, L.Y.M., Staffelbach, G., Poinsot, T.: Large Eddy Simulations of gaseous flames in gas turbine combustion chambers. Progress in Energy and Combustion Science 38(6), $782-817(2012)$

19. Granet, V., Vermorel, O., Lacour, C., Enaux, B., Dugué, V., Poinsot, T.: Large-Eddy Simulation and experimental study of cycle-to-cycle variations of stable and unstable operating points in a spark ignition engine. Combustion and Flame 159(4), 1562-1575 (2012)

20. Hirschfelder, J.O., Curtiss, C.F., Bird, R.B., Mayer, M.G.: Molecular theory of gases and liquids, vol. 26. Wiley New York (1954)

21. Hirt, C.W., Amsden, A.A., Cook, J.L.: An Arbitrary Lagrangian-Eulerian Computing Method for All Flow Speeds. Journal of Computational Physics 135, 203-216 (1997)

22. Jamrozik, A.: Lean combustion by a pre-chamber charge stratification in a stationary spark ignited engine. Journal of Mechanical Science and Technology 29(5), 2269-2278 (2015)

23. Jaravel, T., Riber, E., Cuenot, B., Bulat, G.: Large Eddy Simulation of an industrial gas turbine combustor using reduced chemistry with accurate pollutant prediction. Proceedings of the Combustion Institute 36(3), 1-9 (2016)

24. Lacaze, G., Richardson, E., Poinsot, T.: Large eddy simulation of spark ignition in a turbulent methane jet. Combustion and Flame 156(10), 1993-2009 (2009)

25. Li, H., Karim, G.A., Sohrabi, A.: The Lean Mixture Operational Limits of a Spark Ignition Engine When Operated on Fuel Mixtures. Journal of Engineering for Gas Turbines and Power 131(1), 012801-7 (2009)

26. Lumley, J.L.: Engines: An Introduction. Cambridge University Press (1999)

27. Misdariis, A.: Schémas cinétiques réduits et couplage thermique pour les simulation aux grandes échelles du cliquetis dans les moteurs à piston. Ph.D. thesis, Institut National Polytechnique de Toulouse (2015)

28. Moureau, V.: Simulation aux grandes échelles de l'aérodynamique interne des moteurs à piston. Ph.D. thesis, Ecole Centrale Paris (2004)

29. Moureau, V., Lartigue, G., Sommerer, Y., Angelberger, C., Colin, O., Poinsot, T.: Numerical methods for unsteady compressible multi-component reacting flows on fixed and moving grids. Journal of Computational Physics 202(2), 710-736 (2005)

30. Muller, C., Morcinkowski, B., Schernus, C., Habermann, K., Uhlmann, T.: Development of a pre-chamber for spark ignition engines in vehicle applications. Proceedings of the 4th International Conference on Ignition Systems for Gasoline Engines pp. 261-274 (2018)

31. Nicoud, F., Ducros, F.: Subgrid-Scale Stress Modelling Based on the Square of the Velocity Gradient Tensor. Flow, Turbulence and Combustion 62(3), 183-200 (1999)

32. Pepiot, P.: Automatic strategies to model transportation fuel surrogates. Ph.D. thesis, Stanford University (2008)

33. Peters, N.: The turbulent burning velocity for large-scale and small-scale turbulence. Journal of Fluid Mechanics 384, 107-132 (1999)

34. Petrova, M.V., Williams, F.A.: A small detailed chemical-kinetic mechanism for hydrocarbon combustion. Combustion and Flame 144(3), 526-544 (2006)

35. Prince, J.C., Williams, F.A.: Short chemical-kinetic mechanisms for low-temperature ignition of propane and ethane. Combustion and Flame 159(7), 2336-2344 (2012)

36. Quader, A.A.: What limits lean operation in spark ignition engines-flame initiation or propagation? SAE Technical Paper (1976)

37. Quillatre, P., Vermorel, O., Poinsot, T., Ricoux, P.: Large eddy simulation of vented deflagration. Industrial \& Engineering Chemistry Research 52(33), 11414-11423 (2013)

38. Rochette, B., Collin-Bastiani, F., Gicquel, L., Vermorel, O., Veynante, D., Poinsot, T.: Influence of chemical schemes, numerical method and dynamic turbulent combustion modeling on LES of premixed turbulent flames. Combustion and Flame 191, 417-430 (2018)

39. Roethlisberger, R.P., Favrat, D.: Comparison between direct and indirect (prechamber) spark ignition in the case of a cogeneration natural gas engine, part I: engine geometrical parameters. Applied Thermal Engineering 22, 1217-1229 (2002)

40. Roux, S., Lartigue, G., Poinsot, T., Meier, U., Bérat, C.: Studies of mean and unsteady flow in a swirled combustor using experiments, acoustic analysis and large eddy simulations. Combustion and Flame 141, 40-54 (2005)

41. Saxena, P., Williams, F.A.: Testing a small detailed chemical-kinetic mechanism for the combustion of hydrogen and carbon monoxide. Combustion and Flame 145(1-2), 316-323 (2006) 
42. Schonfeld, T., Rudgyard, M.: Steady and Unsteady Flow Simulations Using the Hybrid Flow Solver AVBP. AIAA Journal 37(11), 1378-1385 (1999)

43. Vermorel, O., Quillatre, P., Poinsot, T.: LES of explosions in venting chamber: a test case for premixed turbulent combustion models. Combustion and Flame 183, 207-223 (2017)

44. Yamaguchi, S., Ohiwa, N., Hasegawa, T.: Ignition and burning process in a divided chamber bomb. Combustion and Flame 59, 177-187 (1985) 